\title{
Examining and Modelling the Determinants of the Rising Land Surface Temperatures in Arabian Desert Cities: An Example from Riyadh, Saudi Arabia
}

\author{
Muhammad Tauhidur RAHMAN1 \\ ${ }^{1}$ King Fahd University of Petroleum and Minerals, Department of City and Regional Planning, Dhahran, SAUDI ARABIA \\ E-mail: mtr@kfupm.edu.sa \\ DOI: 10.24193/JSSP.2018.1.01 \\ https://doi.org/10.24193/JSSP.2018.1.01
}

K e y w o r d s: land surface temperature, population density, land cover, urban heat island, urban climate

\begin{abstract}
A B S T RA C T
The Saudi capital city of Riyadh has experienced rapid population growth and urban expansion over the past 4 decades. One major consequence of such growth is the rising of the city's land surface temperature (LST). This study used Landsat 7 ETM+ sensor data to map the distribution of Riyadh's LST and then examined and modelled the impacts of five contributing factors known to increase urban LST. The contributing factors are size/area and population density of each neighbourhood, along with amounts of impervious surfaces, vegetations, and soil/sand measured through remote sensing indices NDBI, NDVI, and NDBsI. The data were analyzed using Pearson's Product Moment Correlation values, Path Analysis, and Multiple Regression analysis. The result shows that neighbourhood population densities and NDBsI index have strong positive correlations ( $r=0.68$ and $r=0.60)$ with LST. Neighbourhood area showed significant but low positive correlation $(r=0.33)$ and the NDBI and NDVI indices showed strong negative correlations $(r=-0.55$ and $r=-0.64)$ with the LST. The multiple regression model explained about $77 \%$ of the total variation in the LST. The model can be used to predict and simulate future LST distribution for Riyadh as well as other cities in the Kingdom and the region.
\end{abstract}

\section{INTRODUCTION}

Following the oil boom in the 1970s, Riyadh, the capital of the Kingdom of Saudi Arabia has experienced rapid population growth and urban expansions [1], [2]. Rapid population growth has affected the city's environment, and the socio-economic conditions of its residents while massive construction of urban residential and business infrastructures and transportation networks has resulted in rising air pollution, increased frequency of flooding of the city, and rising of the land surface temperature (hereafter LST), [3], [4], [5]. In a desert environment, rising LST and the formation of urban heat island will have tremendous impacts on the health conditions especially in the case of the children, elderly, and the poor residents of the city [6].
The rapid development of geospatial technologies since the 1990s has allowed researchers to examine the changes and effects of urban expansion on LST in cities around the world [7], [8], [9], [10], [11]. LST data derived from remote sensing imageries have achieved better accuracy than those collected from ground-based weather stations [12], [13]. Yuan and Bauer (2007) examined the effect of the impervious surfaces on the seasonal variation of LST for the City of Twin Cities, Minnesota in 2002 [14]. Using Landsat TM and ASTER data, Liu and Zhang (2011) examined the influences of LST on the formation of urban heat islands for the city of Hong Kong [15]. Wang et al. (2018) used Landsat TM and ETM+ data to understand the impacts of urban expansion on LST in Nanjing City for the period between 1985 and 2009 [16]. For the city of Aksu (China), various landscape metrics were used to 
observe their effects on LST using Landsat TM data from 2011 [17]. In the hot city of Fuzhou in China, Yu et al. (2018) examined the cooling effects green spaces in the city's LST [18]. They also found that green spaces connected to waterbodies cooled temperatures more than grassland-based greenspaces [19]. Using Landsat TM data, Chaudhuri and Mishra (2016) compared the organization of land cover and their effects on LST in India and Bangladesh [20].

Studies dealing with the LST over various land uses in Saudi Arabian cities have focused on Jeddah, Yanbu, and Dammam [21], [22], [23]. Using MODIS data, Hereher (2016) examined the trends in the LST and precipitation across the entire Kingdom and found that the LST increased by 0.45 to $1.2^{\circ} \mathrm{C}$ between 2001 and 2014. Assiri (2017) compared the LST derived from MODIS data and found them to be highly correlated with the temperature recorded by the weather stations in the city of Jeddah [13]. Rahman et al. (2017) analyzed long-term Landsat data for the past two decades to examine the land use and land cover changes and their associated changes in LST in the eastern coastal city of Dammam and used them to predict the urban expansion and LST distribution for the year 2026 [22]. For the western industrial city of Yanbu, Aina et al. (2017) used 25 years Landsat data to examine the relationship between LST and the amounts of vegetation and impervious surfaces of the city during 1990 and 2015 [21]. These existing studies have ignored the Capital City of Riyadh, the fastest growing city in the Kingdom where the LST has been influenced by various environmental and anthropogenic factors. For sustainable environmental, economic development, and improvement of public health conditions, it is important to examine the distribution of LST in the city and identify the factors affecting it.

The present study aims to identify the environmental and anthropogenic factors responsible for the spatial variation of LST in 169 neighborhoods of the City of Riyadh for the year 2004. The year 2004 was chosen since it has the most recent neighborhood level population census data publicly available for the city. In the following sections, the factors affecting LST are identified through an extensive literature review and an LST model is proposed in Section 2. A brief description of the study area, data and methods are given in Sections 3 and 4. The results and their analytical discussions are provided in Sections 5 and 6. Finally, the paper concludes by summarizing and giving the path to future research in Section 7.

\section{THEORETICAL FRAMEWORK AND LST MODEL}

Factors affecting LST fall into environmental and human-induced or anthropogenic categories. Numerous studies have identified population growth, measured by increasing population density, at the center of both environmental and anthropogenic factors, directly and indirectly, affecting the variation in the mean LST among global mega-cities in tropical, temperate, arid, and semi-arid climatic conditions [24], [25]. Several studies have also identified urban expansion, imperviousness of land surface, land use/land cover, and city sizes as important predictors of LST variations [26], [27], [28].

In a desert environment, the areas of city neighborhoods and the proportions of bare sandy surfaces they contain are two environmental factors affecting the LST. Bare sand absorbs more direct solar heat and is hotter than the non-sandy soil surface. Hence, neighborhoods with a higher proportion of sands show higher LST. Compactness and areas of cities positively affect the LST as large size neighborhoods with a higher proportion of bare sands experiences higher LST [29].

Most important anthropogenic factor affecting LST is population growth which exerts a strong positive impact on local LST across all climatic conditions [24], [25]. High intensities of daily human activities in megacities also contribute to the increment of LST. In the City of Wuhan in Central China, Lin et al. (2014) found that population density of residential communities strongly and positively influences the LST at the local scale [24]. Also in tropical Shanghai, Chen et al. (2016) found that in areas of high population densities, the LST has increased by at least $3^{\circ} \mathrm{C}$ while areas with lower population density were found to have lower LST [30]. In the semi-arid Indian City of New Delhi, areas of high population density ( $>80$,ooo people per $\mathrm{km}^{2}$ ) had experienced $5^{\circ} \mathrm{C}$ higher LST at night than areas of lower population density and more vacant land [25]. In the desert City of Phoenix, Arizona, Brazel et al. (2000) found that the city's dense residential and industrial areas had higher LST compared to vegetation and water bodies [31]. A recent study in Phoenix also revealed a strong positive correlation between population densities of census blocks and their LST [32].

Among other anthropogenic factors, the quantities of impervious surface/built-up areas, as well as vegetations, also affect the LST. As noted by Chen et al. (2016) and Connors et al. (2013), urban development in the form of expansion of commercial and industrial activities showed strong positive correlation with LST in the cities of Shanghai and Phoenix [30], [33]. In the humid environment such as in the city of Baltimore, impervious surfaces show a positive correlation with LST [31]. However, in contrast, it shows a strong negative relationship with LST in desert cities such as in Dubai, Abu Dhabi, and 5 other desert cities [29], [34], [35], [36]. Impervious surfaces in desert cities appear to be cooler than the surrounding sand as tall buildings cast shadows on the impervious surface and reduce the LST [29], [36]. Urban vegetation, representing human- 
induced land use and land cover changes, was found to be negatively correlated with the LST in a humid environment such as Shanghai as well as in the desert city of Phoenix [30], [32], [37]. Natural and humaninduced vegetation coverage protect the ground surfaces from direct sunlight and lowers the LST.

Based on literature reviews, population density (POPDEN), three remote sensing indices (Normalized Difference Built Index (NDBI), Normalized Difference Vegetation Index (NDVI), and Normalized Difference Bare soil Index (NDBsI)) representing amounts of builtup areas, vegetation, and bare soil, and the city neighborhood size (AREA) were identified as key predictors of variations in LST. These five variables, directly and indirectly, affect the variation in LST. A conceptual model consisting of three paths is proposed here to examine the direct, indirect, and the total effect of the five predictors on the variation of LST in the study area (Fig. 1).

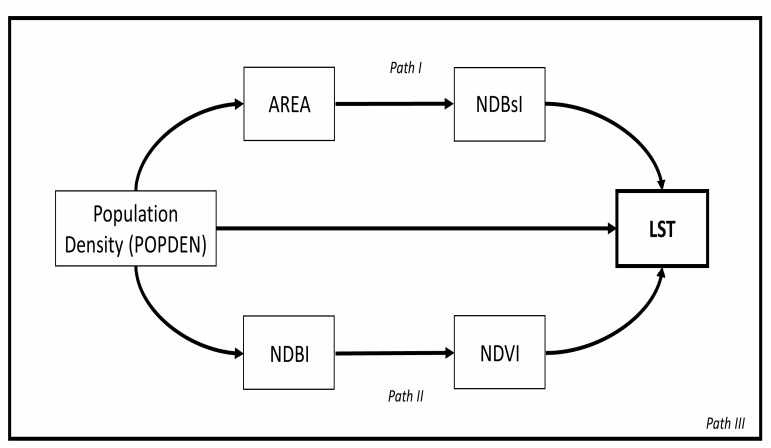

Fig. 1. The proposed LST model consisting of three paths for the study area.

Population density, representing population pressure is central to both paths. The path I, which represents the environmental constraint path, assumes that the effect of population density is filtered through two environmental variables such as neighborhood size (AREA) and bare soil index (NDBsI) to cause the variation in the LST. Path II represents the anthropogenic path and assumes that the effect of population density on LST is filtered through the urban built-up index (NDBI), and the urban vegetation index (NDVI) to cause the variations in the LST. Finally, Path III examines the effect of Population Pressure Mediated via Environmental Constraints and Human Induced Land surface modifications. An LST model for the City of Riyadh was formulated as follows.

The model assumes that population density is the key factor for urban expansion in a city. Increased population density will increase the human activities which will increase the local LST in a city making it warmer (positive effect on LST). Population density will vary with the size of the census neighborhood. Small sized neighborhoods with a large population will have high population density and vice-versa. In a desert environment, bare sand absorbs more heat than shaded impervious surface or vegetation covered surface. Therefore, the mean LST will be higher on bare sand than on the impervious surface and the vegetative coverage of the city built up areas. Thus, it is expected that the sand will increase the LST and the amount of sand will be positively related to the LST. In this regard, city or neighborhood size will also exert a significant impact on the LST, particularly, in case of large neighborhoods where a greater percentage of sand will increase the mean LST. However, it is also possible if the larger neighborhoods are densely populated, then high population density will exert an additional positive effect on the LST unless there is enough vegetation to reduce such effect. Finally, population growth will also induce urban expansion in the form of construction of built-up areas (NDBI) and growth of vegetation either for agriculture and or for shade and recreational purposes. In a desert environment, impervious surface in the urban built-up areas will be cooler than the surrounding bare sandy surface owing to the cooling effect of shadows of urban buildings. Hence, the degree of imperviousness will negatively affect the LST. Similarly, urban vegetation index (NDVI) will also exert a negative impact on LST as the vegetation coverage will reduce the effect of heat.

\section{STUDY AREA}

The city of Riyadh is the capital and the largest city in the Kingdom. It is situated in the central part of the Arabian Peninsula. The greater Riyadh city has an area of almost $5400 \mathrm{~km}^{2}$ distributed over 209 neighbourhoods housing a population of almost 6.5 million and it is expected to exceed 11 million by the year 2020 [38], [39]. However, more than 95\% of the residents reside within 169 neighbourhoods in the eastern and northern parts of the city. These neighbourhoods were selected as the study area for this study (Fig. 2).

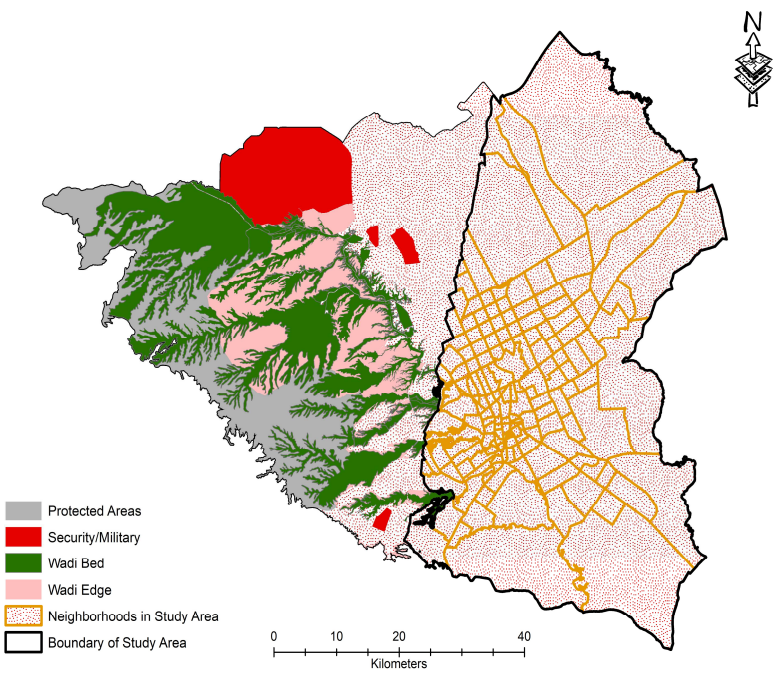

Fig. 2. Study area with the neighbourhoods in the City of Riyadh. 
Together, they have a total area of $2,824 \mathrm{~km}^{2}$ and is administered by 18 municipalities.

Due to its location in the central region of Arabian Peninsula, Riyadh has a subtropical desert climate. The city has dry and hot summers $\left(22-43^{\circ} \mathrm{C}\right)$ and cool and moist winters. Annually the city receives an average rainfall ranging between $100-131 \mathrm{~mm}$ during the months of January and May [40]. The western half of the city is almost vacant due to the western hills as well as the northwest-southeast running $120 \mathrm{~km}$ along the central valley of the Wadi Hanifa.

The eastern parts of the city are flat with a south-eastward slope gradient causing the residents to reside in this part of the city.

\section{DATA AND METHODS}

\subsection{Calculation of LST and remote sensing indices}

In this study, a summertime Landsat 7 ETM+ image (Path: 165; Row: 43) acquired on August 5th, 2004 was used as the primary remote sensing data to map and estimate the distribution of the LST across the study area. The Landsat data was chosen due to its moderate spatial resolution, availability of multiple spectral bands (including thermal) and easily downloadable archival availability. The data was obtained from the United States Geological Survey (USGS) and was delivered in Level 1T format with geometric and radiometric corrections processed through ground control points [41].

The distribution of the LST across the study area for the summer day was calculated using the thermal band of the Landsat ETM+ dataset. To calculate the LST from the ETM+ sensor, the Spectral Radiance Scaling Method was used [42]. The first step of the method involves converting the digital numbers (DNs) from the sensors into the spectral radiance (L $\lambda$ ) using the equation:

$$
L_{\lambda}=\frac{\left(L M A X_{\lambda}-L M I N_{\lambda}\right) \times(D N-Q C A L M I N)}{Q C A L M A X-Q C A L M I N}+\operatorname{LMIN}_{\lambda}
$$

where:

$D N$ - digital number values ranging between o and 255;

$L M I N_{\lambda}-$ minimum spectral radiances;

$L M A X \lambda$ - maximum spectral radiances;

QCALMIN - quantized minimum calibrated pixel values;

QCALMAX - quantized maximum calibrated pixel values.

The spectral radiance was then converted to the brightness temperature (in Kelvin) using the equation [43], [44]:

$$
T_{k}=\frac{K_{2}}{\ln \left(\frac{K_{1}}{L_{\lambda}}+1\right)}
$$

Finally, the temperatures were converted to degrees Celsius.

The population of each neighborhood for the year 2004 was gathered from the Arriyadh Development Authority (ADA). The area in square kilometers for each neighborhood was estimated in ArcGIS and then the population density for each neighborhood was calculated. The mean LST for each neighborhood for 2004 was also calculated using the zonal statistics function of ArcGIS.

To examine the relationships between urban vegetation, built-up area, and bare soils on the LST, three separate remote sensing indices were calculated from the Landsat data. For vegetation detection, the following equation to calculate the NDVI was used [45], [22]:

$$
N D V I=\frac{(\text { Band } 4-\text { Band } 3)}{(\text { Band } 4+\text { Band } 3)}
$$

For examining the distribution of built-up areas across the neighbourhoods, the NDBI index was calculated by the equation [46], [22]:

$$
N D B I=\frac{(\text { Band } 5-\text { Band } 4)}{(\text { Band } 5+\text { Band } 4)}
$$

Finally, the area of bare sandy soil within each neighbourhood was obtained based on the NDBsI index. The NDBsI was calculated based on the equation [45]:

$$
N D B S I=\frac{(\text { Band } 5-\text { Band } 6)}{(\text { Band } 5+\text { Band } 6)}
$$

Once the distribution of the indices was calculated across the entire study area, the mean values of each neighbourhood were calculated in ArcGIS and correlated with the mean LST of each neighbourhood.

Because the variation in LST is the product of complex relationships between many predictors playing within the urban environment, a simple bivariate relationship may not be adequate to explore the actual variation in the LST.

In this study, five predictor variables listed above are taken into consideration and were tested and measured for their single, joint, and cumulative effects on LST using three statistical techniques namely Pearson's Product Moment Correlation, Path Analysis, and Multiple Regression analysis. All the independent variables were tested for multicollinearity. 


\section{RESULTS}

\subsection{Land surface temperature and Pearson's product moment correlation coefficients}

This study first calculated and mapped the distribution of the LST and the three remote sensing indices across the study area. Figure 3 shows these distributions. To examine the effects of population density, urban built-up activities, vegetation, bare soil, and neighbourhood areas on the mean neighbourhood LST, the Pearson's Product Moment Correlation statistic was initially used (Table 1). Population densities of neighbourhoods (POPDEN) showed direct strong positive correlation $(r=0.68)$ with local LST. It indicates that neighbourhoods with high population density showed high LST as population density induces various human activities. The NDBI which indicates the existence of impervious surfaces has a moderately strong negative correlation with LST $(r=-0.55)$. Neighbourhood compactness as measured by its area (AREA) showed significant but low positive correlation ( $r=0.33$ ) with LST indicating that large neighbourhoods with a high percentage of bare sand were essentially warmer than small sized neighbourhoods occupied by built-up impervious surfaces. Urban vegetation index (NDVI) showed strong negative correlation $(r=-0.64)$ with LST as vegetation provides shade and protects the surface from direct sunlight and thereby keeps it cool. In the desert environment, bare sand is always warmer than the impervious surfaces. Neighbourhood bare soil/sand index (NDBsI) shows moderately strong positive correlation $(r=0.60)$ with LST. Likewise, in any climatic and environmental conditions, population growth measured by population density is the key factor for the increment of the LST in the desert environment [29].

Table 1. Correlations between the five independent variables and the mean neighborhood LST.

\begin{tabular}{|c|c|c|c|c|c|}
\hline & LST & POPDEN & NDVI & NDBI & AREA \\
\hline POPDEN & $0.68 * *$ & & & & \\
\hline NDVI & $-0.64 * *$ & $-0.43 * *$ & & & \\
\hline NDBI & $-0.55^{* *}$ & -0.15 & $-0.40^{* *}$ & & \\
\hline AREA & $0.33^{* *}$ & -0.10 & -0.20 * & $-0.35^{* *}$ & \\
\hline NDBsI & $0.60 * *$ & $0.39 * *$ & $-0.41^{* *}$ & $-0.33 * *$ & 0.17 \\
\hline
\end{tabular}

Table 2. Multiple regression and path analysis results showing the direct, indirect, and total effects of the five independent variables on the mean LST.

\begin{tabular}{|c|c|c|c|c|c|c|}
\hline Path & $\begin{array}{l}\text { Dependent } \\
\text { variable }\end{array}$ & $\begin{array}{c}\text { Independent } \\
\text { variable }\end{array}$ & $\begin{array}{l}\text { Direct effects } \\
\text { of driving } \\
\text { forces }(\boldsymbol{\beta})\end{array}$ & $\begin{array}{c}\text { Indirect effects via } \\
\text { mediating variables } \\
\qquad\left(\mathbf{r}_{\mathrm{ij}} \mathbf{p}_{\mathrm{y} . \mathrm{j}}\right)\end{array}$ & $\begin{array}{l}\text { Total effects of } \\
\text { driving forces } \\
\left(\mathbf{r}_{\mathrm{ij}}\right)\end{array}$ & Change in $R^{2}$ \\
\hline \multirow{3}{*}{$\begin{array}{l}\text { Path I } \\
\left(r^{2}=0.67\right)\end{array}$} & \multirow{3}{*}{ LST } & POPDEN & 0.60 & -0.03 (AREA) & 0.57 & 0.462 \\
\hline & & AREA & 0.33 & 0.06 (NDBsI) & 0.39 & 0.61 \\
\hline & & NDBsI & 0.28 & 0.11 (AREA) & 0.39 & 0.67 \\
\hline \multirow{4}{*}{$\begin{array}{l}\text { Path II } \\
\left(r^{2}=0.71\right)\end{array}$} & \multirow{3}{*}{ LST } & POPDEN & 0.51 & 0.05 (NDBI) & 0.56 & 0.46 \\
\hline & & NDBI & -0.35 & $-0.14(\mathrm{NDVI})$ & -049 & 0.66 \\
\hline & & NDVI & -0.28 & $-0.11(\mathrm{NDBI})$ & -0.39 & 0.71 \\
\hline & \multirow{5}{*}{ LST } & POPDEN & 0.50 & $-0.04(\mathrm{NDBI})$ & 0.46 & 0.46 \\
\hline \multirow{4}{*}{$\begin{array}{l}\text { Path III } \\
\left(r^{2}=0.77\right)\end{array}$} & & NDBI & -0.25 & -0.07 (AREA) & -0.32 & 0.66 \\
\hline & & AREA & 0.21 & 0.04 (NDVI) & 0.25 & 0.71 \\
\hline & & NDVI & -0.21 & 0.08 (NDBsI) & -0.13 & 0.75 \\
\hline & & NDBsI & 0.17 & -0.07 (NDVI) & 0.10 & 0.77 \\
\hline
\end{tabular}

\subsection{Path I: Effects of the local environment}

In the path analysis, Path $I$, examined the effect of population densities on the LST as such effect was mediated by two environmental variables such as AREA and NDBsI. In the desert city of Riyadh, population growth demanded more human activities which initially increased the LST. However, many large neighbourhoods had low population density and a higher percentage of bare sand resulting in higher mean LST. Multiple regression of the LST against the three independent variables has explained $67 \%$ of the total variation in the LST (Table 2). As for the direct effects (standardized regression coefficients or $\beta$-value), POPDEN has emerged as the most powerful $(\beta=0.60)$ factor responsible for increasing the LST and it was followed by AREA $(\beta=0.33)$, and NDBsI $(\beta=0.28)$ variables. 


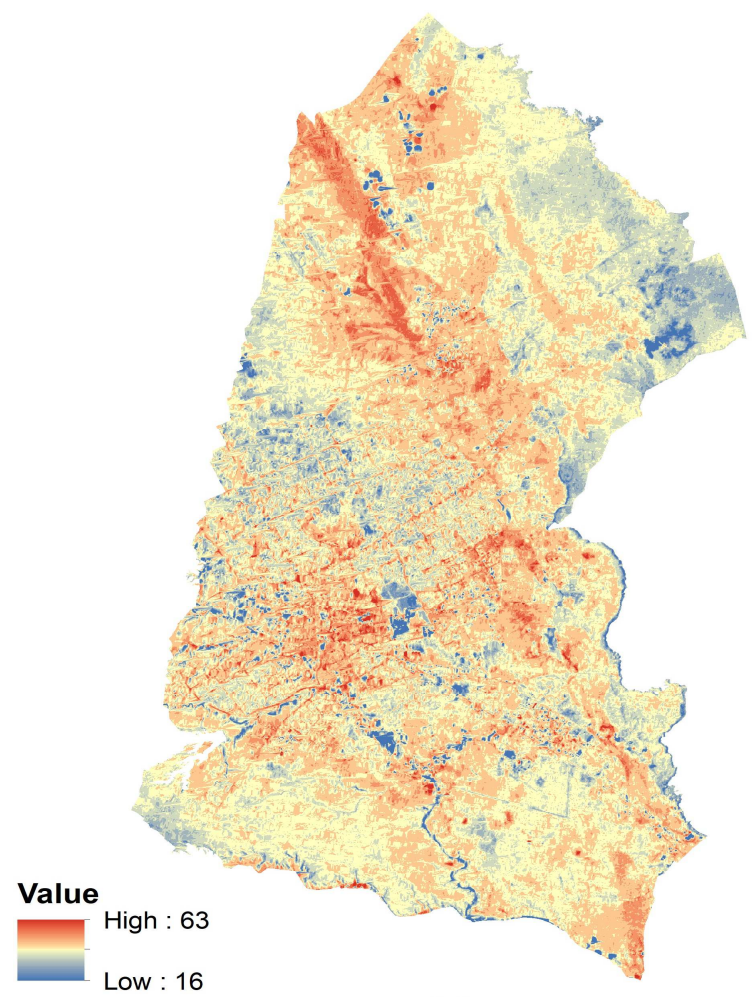

(a)

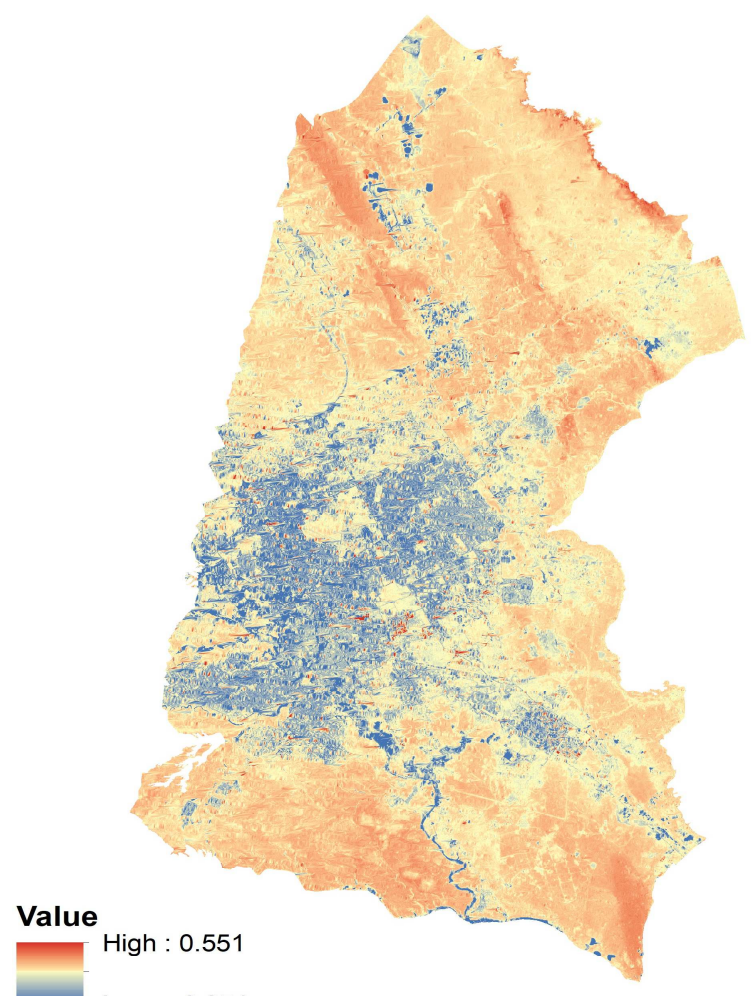

(c)

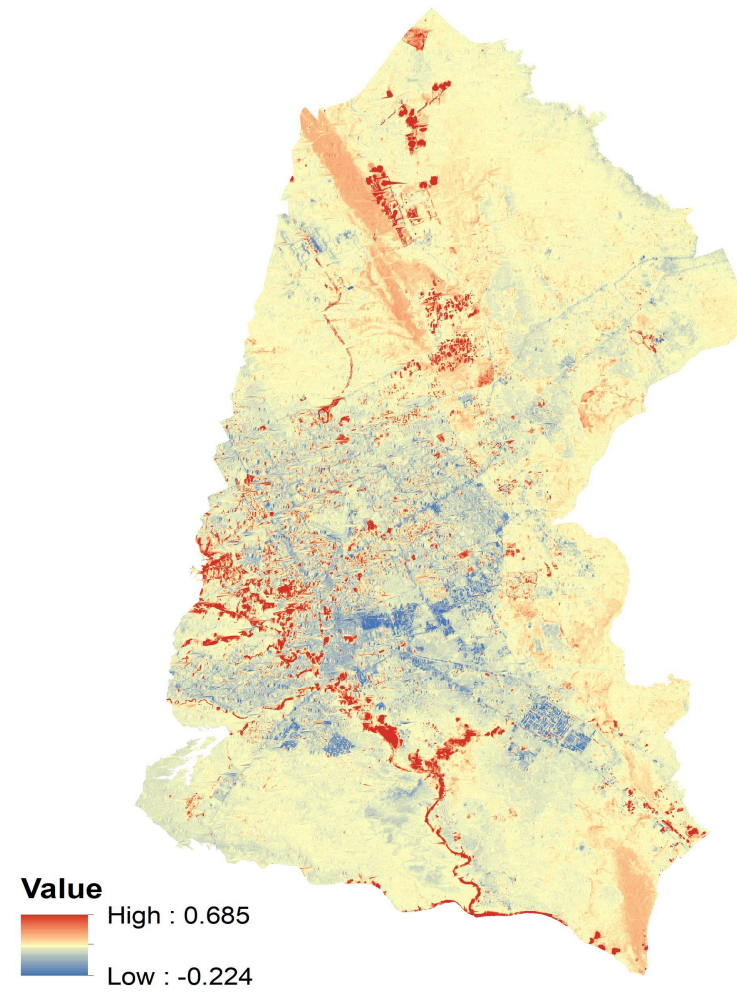

(b)

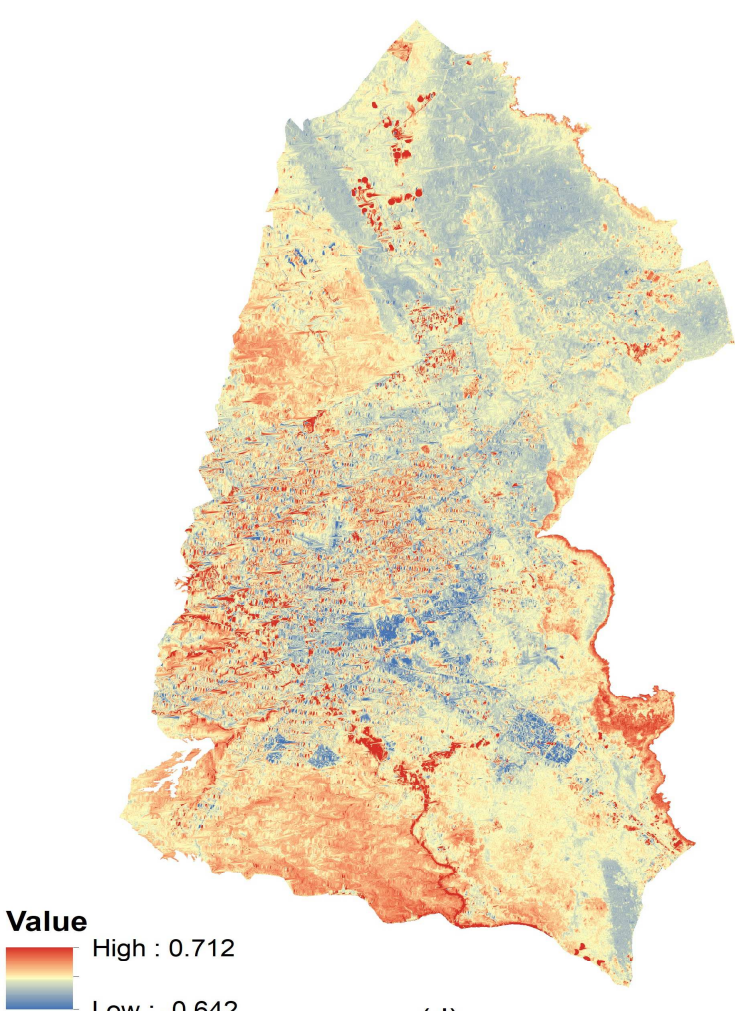

(d)

Fig. 3. Distribution of the (a). LST; (b). NDVI; (c). NDBI; (d) NDBsI across the study area.

It was observed that the direct effect of POPDEN was strongly positive. However, when mediated through the AREA, it slightly decreased because the smaller neighbourhoods with dense residential buildings experienced more shading which somewhat lessened the LST. On the other hand, the direct effects of AREA and NDBsI on LST were increased due to the existence of several larger 
neighbourhoods containing a larger proportion of bare soil which in turn increased the LST (see Table 2).

\subsection{Path II: Effects of imperviousness and vegetation}

The Path II examined the effect of anthropogenic predictors (POPDEN, NDBI, and NDVI) on the LST in the study area. Multiple regression of LST against the above three independent variables has explained about $71 \%$ of the variation in LST. POPDEN has the most powerful direct effect $(\beta=0.51)$ on the increment of LST; and it was followed by NDBI ( $\beta=-$ o.35), and NDVI ( $\beta=-0.28)$ variables. It was observed that the direct effect of POPDEN was strongly positive. However, both NDBI and NDVI have strong direct negative effects on the LST. The indirect effects of all three variables have combinedly increased their total effects on the LST. City neighbourhoods with high population density are supposed to be warmer. However, in the City of Riyadh, high imperviousness of surface in smaller compact downtown neighbourhoods occupied by tall buildings, parking lots, business establishments, and vegetation keeps the local surface temperature cooler than bigger bare sandy neighbourhoods in the outskirt areas.

\subsection{Path III: Combined effect of environment and human actions}

Finally, Path III assessed the total combined effects of all five environmental and anthropogenic independent variables specified in the model earlier. Step-wise multiple regression analysis has explained about $77 \%$ of the total variance in the LST. In the first step, POPDEN entered in the model and by explaining $46 \%$ of the total variance and emerged as the most important predictor increasing the local surface temperature. In the second step, NDBI entered in the model and explained an additional $20 \%$ of the total variance and emerged as the second most important predictor of the LST. AREA entered in the model next and explained another $5 \%$ of the total variance of the LST. In the fourth and fifth steps, NDVI and NDBsI entered and explained respectively $4 \%$ and $2 \%$ of the total variation in the LST.

\section{DISCUSSIONS}

The study results suggest that over time as the City of Riyadh grew spatially, major construction of commercial and residential buildings, parking lots, and vegetation on the street sides and in recreational areas have resulted in the cooling of LST in the central part of the city. The smaller densely populated neighbourhoods had experienced high LST. In contrast, however, the larger neighbourhoods in the city outskirts, where population and vegetation were sparse, had experienced higher local surface temperature due to the presence of a higher percentage of bare sand.

The study findings are interesting as they provide the scope of comparing the LST of a desert region with those in the tropical and subtropical cities. As observed in tropical and subtropical cities, the LST tends to be higher in the central downtown areas where impervious surfaces absorb more heat during the day than their surrounding clay soils. Contrary to them are the desert cities of Phoenix (Arizona), Abu Dhabi, and Dubai where downtowns with a high percentage of the impervious surface occupied by high rise buildings, and vegetation are cooler than their bare sandy desert outskirts [34], [37], [47].

In these latter cities, tall buildings and green vegetation provide shades and protect the impervious surfaces from direct solar heating resulting in lower LST. The present study reveals that Riyadh is not an exception to this phenomenon and that the downtown area in the south-central part of the city is much cooler than the vacant sandy desert in the north-eastern part of the city.

In examining the direct, indirect, and the combined effects of all five independent variables on the LST, the results suggest that like any other desert cities, population growth, compactness of city (size) and existence of sand around the city can increase the city LST while the degree of urban surface imperviousness and vegetation coverage would lower the LST in Riyadh [29]. The high population density was strongly and positively associated with the LST as observed in tropical and sub-tropical cities of Wuhan (China), and New Delhi (India) [24], [25].

So, the densely populated city downtowns had higher LST than the city urban fringe areas. This situation was reversed in the case of Riyadh and other desert cities where population density alone shows a strong positive relation with LST. However, over time, when the city land gradually being occupied by increasing degree of impervious surfaces and vegetation coverages, the LST may tend to decline to such an extent that population density at the city centres may show a negative correlation with the LST as observed in Phoenix.

The most important phenomenon that can be attributed to the inverse urban heat-island effect for desert cities is heated reflectance and absorbability of desert sands that surround the city as sands are hotter than the vegetation and impervious surfaces [29], [48]. These findings support the existing results from other desert cities such as Phoenix, Abu Dhabi, Erbil, and Dubai [34], [36], [47]. 


\section{CONCLUSIONS}

The present study has examined the spatial variations in LST for the city of Riyadh for the year 2004. The study has identified neighbourhood population densities, areas, vegetation, built-up areas, and sand indices as the key predictors of local LST. While neighbourhood areas and population densities along with the bare sand index contributed to increasing the local surface temperature, vegetation and surface imperviousness in the city tends to lower it in this desert Capital city. The proposed model is an initial attempt to explain the causes of local LST variation and has several significant contributions. First, it is the first study to propose and test an initial LST model by incorporating 5 predictor variables for any city in the Middle East and Saudi Arabia in general and for Riyadh in particular. The results are comparable to existing LST studies done elsewhere, including those conducted in the desert cities.

Second, the model can be utilized to predict the distribution of LST based on hypothetical parameters for Riyadh in the future. This will allow city planners and government officials to visualize and take precautionary measures to reduce the LST at the local neighbourhood scale. The results can be combined with other socio-demographic data to map and examine the social vulnerability to LST within the city. Finally, the parameters of the models can be used and compared to other cities of the Kingdom as well.

This study, however, does have few limitations. The proposed model was tested by incorporating an only limited number of environmental and anthropogenic variables that have explained only $77 \%$ of the variations of the LST indicating the existence of more predictors of LST. As revealed in the literature, some other possible predictors of LST would be socioeconomic (e.g., age, education, income, ownership of automobiles of city residents, land use patterns, and residential housing types), environmental variables such as air pollution, carbon emission from automobiles and industries, and seasonal variations of rainfall [32]. The present study could not incorporate these variables in modelling LST for Riyadh due to the lack of reliable data sets. Also, the data pertaining to population and population density is over a decade old (2004). It would be interesting to examine the changes in the LST and the model parameters using recent neighbourhood level population data. The model should be further improved by incorporating seasonal as well as recent LST data values and additional environmental and anthropogenic variables which are not considered in this study.

\section{ACKNOWLEDGEMENTS}

The author acknowledges and appreciates the financial support provided by King Abdulaziz City for
Science and Technology (KACST) through the Science \& Technology Unit at King Fahd University of Petroleum \& Minerals (KFUPM) for funding this work through project number 13-ENE198-04 as part of the "National Science, Technology and Innovation Plan (NSTIP)" program.

\section{REFERENCES}

[1] Ashwan, M. S. A., Salam, A. A., Mouselhy, M. A. (2012), Population growth, structure and distribution in Saudi Arabia, In: Humanities and Social Sciences Review, vol. 1, issue 4, pp. 33-46.

[2] Albatel, A. H. (2005), Population Growth and Economic Development in Saudi Arabia, In: Scientific Journal of King Faisal University (Humanities and Management Sciences), vol. 6, issue 2, pp. 341-374.

[3] Rahman, M. T., Aldosary, A., Nahiduzzaman, K. M., Reza, I. (2016), Vulnerability of flash flooding in Riyadh, Saudi Arabia. In: Natural Hazards, vol. 84, issue 3, pp. 1807-1830. DOI:https://doi.org/10.1007/ s11069-016-2521-8

[4] Taha, S. (2014), Riyadh ranked among most polluted cities globally. Available online at: http://www.arabnews.com/news/538861.

[5] Nahiduzzaman, K. M., Aldosary, A. S., Rahman, M. T. (2015), Flood induced vulnerability in strategic plan making process of Riyadh city. In: Habitat International, vol. 49, pp. 375-385. DOI: http://dx.doi.org/10.1016/j.habitatint.2015.05.034

[6] Lai, L. W., Cheng, W. L. (2010), Urban heat island and air pollution--an emerging role for hospital respiratory admissions in an urban area. In: Journal of Environmental Health, vol. 72, pp. 32-35.

[7] Srivastava, P. K., Majumdar, T. J., Bhattacharya, A. K. (2009), Surface temperature estimation in Singhbhum Shear Zone of India using Landsat-7 ETM+ thermal infrared data. In: Advances in Space Research, vol. 43, issue 10, pp. 1563-1574. DOI: https://doi.org/10.1016/j.asr.2009.01.023

[8] Sun, H., Forsythe, W., Waters, N. (2007), Modeling Urban Land Use Change and Urban Sprawl: Calgary, Alberta, Canada. In: Networks and Spatial Economics, vol. 7, issue 4, pp. 353-376. DOI: https://doi.org/10.1007/s11067-007-9030-y

[9] Spiekermann, R., Brandt, M., Samimi, C. (2014), Woody vegetation and land cover changes in the Sahel of Mali (1967-2011). In: International Journal of Applied Earth Observation and Geoinformation, vol. 34, issue December, pp. 113-121. DOI: http://dx.doi.org/10.1016/j.jag.2014.08.007

[10] Rahman, M. T. (2016), Detection of Land Use/Land Cover Changes and Urban Sprawl in AlKhobar, Saudi Arabia: An Analysis of Multi-Temporal Remote Sensing Data. In: ISPRS International Journal of Geo-Information, vol. 5, issue 2, pp. 15. DOI: https://doi.org/10.3390/ijgi5020015 
[11] Ahmed, B., Kamruzzaman, M., Zhu, X., Rahman, M. S., Choi, K. (2013), Simulating Land Cover Changes and Their Impacts on Land Surface Temperature in Dhaka, Bangladesh. Remote Sensing, vol. 5, pp. 5969-5998.

[12] Nichol, J. E., To, P. H. (2012), Temporal characteristics of thermal satellite images for urban heat stress and heat island mapping. In: ISPRS Journal of Photogrammetry and Remote Sensing, vol. 74, pp. 153-162. DOI:https://doi.org/10.1016/j.ispr sjprs.2012.09.007

[13] Assiri, M. (2017), Assessing MODIS Land Surface Temperature (LST) Over Jeddah. In: Polish Journal of Environmental Studies, vol. 26, issue 4, pp. 1461-1470. DOI: https://doi.org/10.15244/pjoes/68960

[14] Yuan, F., Bauer, M. E. (2007), Comparison of impervious surface area and normalized difference vegetation index as indicators of surface urban heat island effects in Landsat imagery. In: Remote Sensing of Environment, vol. 106, issue 3, pp. 375-386. DOI: https://doi.org/10.1016/j.rse.2006.09.003

[15] Liu, L., Zhang, Y. (2011), Urban heat island analysis using the Landsat TM data and ASTER Data: A case study in Hong Kong. In: Remote Sensing, vol. 3, issue 7, pp. 15351552. DOI: https://doi.org/10.3390/ rs3071535

[16] Wang, S., Ma, Q., Ding, H., Liang, H. (2018), Detection of urban expansion and land surface temperature change using multi-temporal Landsat images. In: Resources, Conservation and Recycling, vol. 128, pp. 526-534. DOI:https://doi.org/10.1016/ j.resconrec.2016.05.011

[17] Maimaitiyiming, M., Ghulam, A., Tiyip, T., Pla, F., Latorre-Carmona, P., Halik, Ü., Sawut, M., Caetano, M. (2014), Effects of green space spatial pattern on land surface temperature: Implications for sustainable urban planning and climate change adaptation. In: ISPRS Journal of Photogrammetry and Remote Sensing, vol. 89, pp. 59-66. DOI:10.1016/ j.isprsjprs.2013.12.010

[18] Yu, Z., Guo, X., Zeng, Y., Koga, M., Vejre, H. (2018), Variations in land surface temperature and cooling efficiency of green space in rapid urbanization: The case of Fuzhou city, China. In: Urban Forestry and Urban Greening, vol. 29, pp. 113-121. DOI: https://doi. org/10.1016/j.ufug.2017.11.008

[19] Yu, Z., Guo, X., Jørgensen, G., Vejre, H. (2017), How can urban green spaces be planned for climate adaptation in subtropical cities? In: Ecological Indicators, vol. 82, pp. 152-162. DOI:https://doi. org/10.1016/j.ecolind.2017.07.002

[20] Chaudhuri, G., Mishra, N. B. (2016), Spatiotemporal dynamics of land cover and land surface temperature in Ganges-Brahmaputra delta: A comparative analysis between India and Bangladesh. In: Applied Geography, vol. 68, pp. 68-83. DOI: https://doi.org/10.1016/j.apgeog.2016.01.002
[21] Aina, Y., Parvez, I., Balogun, A.-L. (2017), Examining the Effect of Land Use on the Spatiotemporal Dynamics of Urban Temperature in an Industrial City: A Landsat Imagery Analysis. In: Global Changes and Natural Disaster Management: Geo-information Technologies, Pirasteh, S.; Li, J., [editors] Springer International Publishing, Switzerland, pp. 1-23. DOI:https://doi.org/10.1007/ 978-3-319-51844-2_1

[22] Rahman, M. T., Aldosary, A. S., Mortoja, M. G. (2017), Modeling Future Land Cover Changes and Their Effects on the Land Surface Temperatures in the Saudi Arabian Eastern Coastal City of Dammam. In: Land, vol. 6, pp. 36. DOI: https://doi.org/10.339o/ land6020036

[23] Hereher, M. E. (2016), Recent trends of temperature and precipitation proxies in Saudi Arabia: implications for climate change. In: Arabian Journal of Geosciences, vol. 9, pp. 575. DOI: https:// doi.org/10.1007/s12517-016-2605-5

[24] Lin, L., Tan, Y., Ying, S., Yu, Z., Li, Z., Lan, H. (2014), Impact of land cover and population density on land surface temperature: case study in Wuhan, China. In: Journal of Applied Remote Sensing, vol. 8, issue 1, pp. 084993. DOI:https://doi.org/ 10.1117/1.JRS.8.084993

[25] Mallick, J., Rahman, A. (2012), Impact of population density on the surface temperature and micro-climate of Delhi. In: Current Science, vol. 102, issue 12, pp. 1708-1713.

[26] Walawender, J., Szymanowski, M., Hajto, M., Bokwa, A. (2014), Land Surface Temperature Patterns in the Urban Agglomeration of Krakow (Poland) Derived from Landsat-7/ETM+ Data. In: Pure and Applied Geophysics, vol. 171, issue 6, pp. 913940. DOI: https://doi.org/10.1007/s00024-013-0685-7 [27] Zhou, B., Rybski, D., Kropp, J. P. (2017), The role of city size and urban form in the surface urban heat island. In: Scientific Reports, vol. 7, issue 4791, pp. 1-9. DOI: https://doi.org/10.1038/s41598-017-04242-2 [28] Morabito, M., Crisci, A., Messeri, A., Orlandini, S., Raschi, A., Maracchi, G., Munafò, M. (2016), The impact of built-up surfaces on land surface temperatures in Italian urban areas. In: Science of the Total Environment, vol. 551-552, pp. 317-326. DOI: https://doi.org/10.1016/j.scitotenv. 2016.02.029

[29] Fan, C., Myint, S. W., Kaplan, S., Middel, A., Zheng, B., Rahman, A., Huang, H., Brazel, A., Blumberg, D. G. (2017), Understanding the Impact of Urbanization on Surface Urban Heat Islands $-A$ Longitudinal Analysis of the Oasis Effect in Subtropical Desert Cities. In: Remote Sensing, vol. 9, pp. 672. DOI: https://doi.org/10.3390/rs9070672

[30] Chen, L., Jiang, R., Xiang, W. N. (2016), Surface Heat Island in Shanghai and its Relationship 
with Urban Development from 1989 to 2013. In: Advances in Meteorology, vol. 2016, pp. 15. DOI: http://dx.doi.org/10.1155/2016/9782686

[31] Brazel, A., Selover, N., Vose, R., Heisler, G. (2000), The tale of two climates - Baltimore and Phoenix urban LTER sites. In: Climate Research, vol. 15, issue 2, pp. 123-135. DOI:http://dx.doi.org/ 10.3354/cro15123

[32] Li, X., Li, W., Middel, A., Harlan, S. L., Brazel, A. J., Turner, B. L. (2016), Remote sensing of the surface urban heat island and land architecture in Phoenix, Arizona: Combined effects of land composition and configuration and cadastraldemographic-economic factors. In: Remote Sensing of Environment, vol. 174, pp. 233-243. DOI: https://doi. org/10.1016/j.rse.2015.12.022

[33] Connors, J. P., Galletti, C. S., Chow, W. T. L. (2013), Landscape configuration and urban heat island effects: Assessing the relationship between landscape characteristics and land surface temperature in Phoenix, Arizona. In: Landscape Ecology, vol. 28, issue 2, pp. 271-283. DOI: https://doi.org/10.1007/s10980-012-9833-1

[34] Lazzarini, M., Marpu, P. R., Ghedira, H. (2013), Temperature-land cover interactions: The inversion of urban heat island phenomenon in desert city areas. In: Remote Sensing of Environment, vol. 130, pp. 136-152. DOI: https://doi.org/10.1016/ j.rse.2012.11.007

[35] Frey, C., Rigo, G., Parlow, E., Marcal, A. (2006), The cooling effect of cities in a hot and dry environment. In Global Developments in Environmental Earth Observation from Space. Proceedings of the $25^{\text {th }}$ Symposium of the EuropeanAssociation of Remote Sensing Laboratories (EARSeL); pp. 169-174.

[36] Rasul, A., Balzter, H., Smith, C. (2015), Spatial variation of the daytime Surface Urban Cool Island during the dry season in Erbil, Iraqi Kurdistan, from Landsat 8. In: Urban Climate, vol. 14, pp. 176186. https://doi.org/10.1016/j.uclim.2015.09.001

[37] Myint, S. W., Wentz, E. A., Brazel, A. J., Quattrochi, D. A. (2013), The impact of distinct anthropogenic and vegetation features on urban warming. In: Landscape Ecology, vol. 28, issue 5, pp. 959-978. DOI: https://doi.org/10.1007/s10980-0139868-y

[38] General Authority for Statistics Population Statistics. Available online at: http://www.stats.gov.sa /en

[39] Khan, M. G. A. (2002), Riyadh population to cross $11 \mathrm{~m}$ by 2020. Available online at: http://www.arabnews.com/node/225397 (accessed Jan 1, 2017).

[40] Qhtani, A. M., Al Fassam, A. N. (2011), ArRiyadh Geospatial Urban Information System and Metropolitan Development Strategy for ArRiyadh. In: ESRI International User Conference, pp. 1-26.

[41] USGS LANDSAT 8 (L8) DATA USERS HANDBOOK Version 1.o June 2015; 2015; Vol. 8.

[42] Coll, C., Galve, J. M., Sánchez, J. M., Caselles, V. (2010), Validation of Landsat-7/ETM + Thermal-Band Calibration and Atmospheric Correction with Ground-Based Measurements. In: IEEE Transactions on Geoscience and Remote Sensing, vol. 48, issue 1, pp. 547-555. DOI:https://doi.org/ 10.1109/TGRS.2009.2024934

[43] Ma, Y., Kuang, Y., Huang, N. (2010), Coupling urbanization analyses for studying urban thermal environment and its interplay with biophysical parameters based on TM/ETM+ imagery. In: International Journal of Applied Earth Observation and Geoinformation, vol. 12, issue 2, pp. 110-118. DOI: https://doi.org/10.1016/j.jag.2009.12.002

[44] Wukelic, G. E., Gibbons, D. E., Martucci, H. P., Foote, H. P. (1989), Radiometric calibration of Landsat Thematic Mapper thermal band. In: Remote Sensing of Environment, vol. 28, pp. 339-347. DOI: https://doi.org/10.1016/0034-4257(89)90125-9

[45] Chen, X.-L., Zhao, H.-M., Li, P.-X., Yin, Z.-Y. (2006), Remote sensing image-based analysis of the relationship between urban heat island and land use/cover changes. In: Remote Sensing of Environment, vol. 104, issue 2, pp. 133-146. DOI: https://doi.org/10.1016/j.rse.2005.11.016

[46] Zha, Y., Gao, J., Ni, S. (2003), Use of normalized difference built-up index in automatically mapping urban areas from TM imagery. In: International Journal of Remote Sensing, vol. 24, issue 3, pp. 583-594. DOI: https://doi.org/10.1080/ 01431160304987

[47] Abdi, A. (2012), Using Landsat ETM+ to assess land cover and land surface temperature change in Dubai between 1999 and 2009. Available online at: http://www.hakimabdi.com/20120729/using-landsatetm-to-assess-land-cover-and-land-surface-

temperature-change-in-dubai-between-1999-and-2009. [48] Fathizad, H., Tazeh, M., Kalantari, S., Shojaei, S. (2017), The investigation of spatiotemporal variations of land surface temperature based on land use changes using NDVI in southwest of Iran. In: Journal of African Earth Sciences, vol. 134, pp. 249-256. DOI: https://doi.org/10.1016/j.jafrearsci. 2017.06.007 